\section{Hiperaldosteronismo Primário Revisitado}

\section{RESUMO}

Esta apresentação tem o objetivo de discutir o tema "hiperaldosteronismo primário" (HAP). Inicialmente, serão apresentados os dados clínicos, laboratoriais, radiológicos e o resultado do estudo anátomo-patológico do tumor de uma paciente portadora de "aldosteronoma", seguindo-se uma discussão centrada em três pontos principais: 1) a investigação de HAP em pacientes com hipertensão arterial; 2) o diagnóstico etiológico do HAP; e 3) o tratamento das várias formas de apresentação do HAP. (Arq Bras Endocrinol Metab 2001;45/3:285-301)

Unitermos: Hiperaldosteronismo primário; Aldosteronoma; Hipertensão arterial; Hipocalemia; Relação aldosterona:renina; Tumor adrenal.

\section{APRESENTAÇÃO DO CASO}

\section{Dra. Vanessa Quintas Passos (Residente de $1^{\circ}$ ano, Serviço de Endocrinologia e Metabologia do HC-FMUSP)}

U MA MULHER BRANCA DE 30 ANOS, apresentou um quadro agudo de fraqueza nas mãos que progrediu, rapidamente, para os membros superiores e inferiores, tronco e região cervical. Foi atendida no pronto socorro do HCFMUSP, onde constatou-se tetraparesia, associada à hipertensão arterial e à hipocalemia. Medicada com cloreto de potássio $(\mathrm{KCl})$ intravenoso, a paciente apresentou melhora dos sintomas sendo, em seguida, transferida para o Serviço de Endocrinologia e Metabologia do HC-FMUSP.

Referia hipertensão arterial há 2,5 anos, mas negava poliúria e polidpsia. Cinco meses antes do episódio relatado, a paciente apresentou quadro semelhante, sendo atendida em outro serviço de onde trazia o seguinte relatório: quadro de tetraparesia grau 4, com hiporreflexia global e hipoestesia subjetiva. Potássio: $2,0 \mathrm{mEq} / \mathrm{L}$; CPK: 7.759U/L. Tinha sido medicada com injeção intravenosa de $\mathrm{KCl}$, apresentando reversão do quadro. Sua mãe é hipertensa. P: 82bpm.

Exame físico: PA: 150xl00 mmHg (posição supina e ortostática);

Diminuição da força muscular nos membros com hiporreflexia global. Fundo de olho normal.

Avaliação laboratorial: $\mathrm{Hb}$ : 11,3g/dL; Leucócitos: $7.300 / \mathrm{mm}^{3}$. Plaquetas: 261.000.

\author{
Vanessa Quintas Passos \\ Leandro Aurélio L. Martins \\ Maria Adelaide A. Pereira \\ Claudio E. Kater
}

\begin{abstract}
Serviço de Endocrinologia e Metabologia (VQP, MAAP) e Divisão de Anatomia Patológica (LALM), Hospital das Clínicas da Faculdade de Medicina da Universidade de São Paulo (HC-FMUSP) e Disciplina de Endocrinologia e Metabologia (CEK), Universidade Federal de São Paulo (UNIFESPEPM), São Paulo, SP
\end{abstract}

Recebido em 30/08/00

Revisado em 16/03/01 Aceito em 30/03/01

Local e data da reunião: Serviço de Endocrinologia e Metabologia do Hospital das Clinicas da Faculdade de Medicina da Universidade de São Paulo (HC-FMUSP) em 17 de Agosto de 2000.

Edição: Maria Adelaide Albergaria Pereira 
Glicemia: $87 \mathrm{mg} / \mathrm{dL}$; Hemoglobina glicosilada: 4,5\%; Colesterol: $169 \mathrm{mg} / \mathrm{dL}$; HDL: $40 \mathrm{mg} / \mathrm{dL}$; LDL: $110 \mathrm{mg} / \mathrm{dL}$; Triglicérides: $94 \mathrm{mg} / \mathrm{dL} ;$ Uréia: $10 \mathrm{mg} / \mathrm{dL}$; Creatinina: $0,7 \mathrm{mg} / \mathrm{dL}$; Calcio iônico: $4,2 \mathrm{mg} / \mathrm{dL}$; P: 1,4mg/dL; Na: $145 \mathrm{mEq} / \mathrm{L}$ (normal: $135-145 \mathrm{mEq} / \mathrm{L}$ ); $\mathrm{K}: 1,7 \mathrm{mEq} / \mathrm{L}$ (normal: 3,5-5mEq/L); CPK: $8.405 \mathrm{U} / \mathrm{L}$ (normal: 24-173U/L); Cortisol basal: 11,6 $\mu \mathrm{g} / \mathrm{dL}$ e após $2 \mathrm{mg}$ VO de dexametasona: 1,9 $\mathrm{gg} / \mathrm{dL}$; DHEAS: $110 \mu \mathrm{g} / \mathrm{dL}$; Testosterona: 14ng/dL; Metanefrinas urinárias: $0,83 \mu \mathrm{g} / \mathrm{mgCr}$ (normal: $0,05-1,2 \mu \mathrm{g} / \mathrm{mgCr}$ ); Aldosterona (A): 46ng/dL (normal, em posição supina: 9-16ng/dL); Atividade plasmática de renina (APR): $<0,2 \mathrm{ng} / \mathrm{mL} / \mathrm{h}$ (normal, em posição supina: 0,22,8ng/mL/h); Relação A:APR: >230.

Após infusão intravenosa de solução salina isotônica ( $2 \mathrm{~L} \mathrm{em} 2 \mathrm{hs}$ ), a aldosterona manteve-se elevada em 59,2ng/dL, confirmando o diagnóstico de hiperaldosteronismo primário (HAP).

Tomografia computadorizada (TC) de abdome revelou um tumor de $3 \mathrm{~cm}$ de diâmetro na adrenal esquerda. Após ter sido medicada e compensada com espironolactona e $\mathrm{KCl}$, a paciente foi submetida com sucesso à adrenalectomia por via laparoscópica.

\section{ESTUDO ANÁTOMO-PATOLÓGICO}

\section{Dr. Leandro Aurélio L. Martins (Residente de $2^{\circ}$ ano, Divisão de Anatomia Patológica do HC- FMUSP)}

O exame macroscópico mostrava glândula suprarenal pesando $10 \mathrm{~g}$ e exibindo tumor encapsulado medindo $3,3 \mathrm{~cm}$ no seu maior eixo, de coloração amarelo-ouro (figura 1). O exame histopatológico exibe neoplasia em arranjo alveolar, constituída por duas populações de células com citoplasma abundante e com citoplasma eosinófilo. Observava-se área de hiperplasia da camada glomerulosa, adjacente a neoplasia e ausência de sinais de malignidade.

Os seguintes marcadores imuno-histoquímicos foram positivos: vimentina, sinaptofisina, $35 \mathrm{BH} 1 \mathrm{l}$ e 34BE12, enquanto AEl/AE3, cromogranina e ACTH, foram negativos.

O quadro histopatológico, correlacionado ao perfil imuno-histoquímico e aos dados clínico-laboratoriais é compatível com o diagnóstico de adenoma adrenocortical produtor de aldosterona ("aldosteronoma").

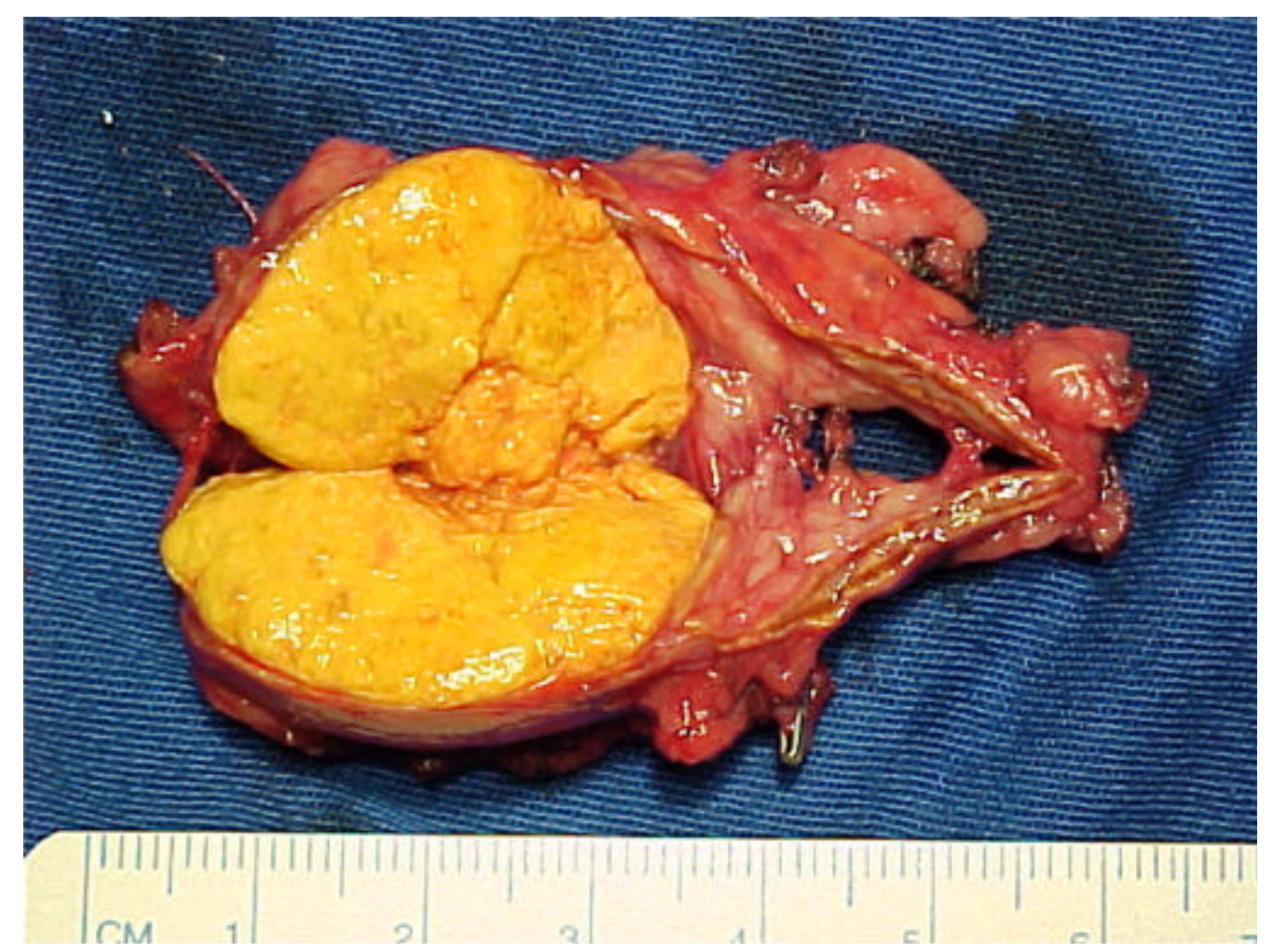

Figura 1: Aspecto macroscópico do tumor da supra-renal esquerda. 


\section{DISCUSSÃO}

Prof. Dr. Claudio E. Kater (Professor Adjunto, Disciplina de Endocrinologia e Metabologia, UNIFESP)

O hiperaldosteronismo primário (HAP), descrito por Jerome Conn em 1955, acompanhou-se de algumas novidades ao longo desses 45 anos, todas relativamente importantes do ponto de vista classificatório, na medida em que novas doenças que envolvem a síndrome do HAP vem sendo reportadas. Além do tumor descrito no caso índice - o "aldosteronoma" característico da síndrome de Conn -, definiram-se outros subgrupos que produziam o quadro sindrômico de HAP, como as "hiperplasias", uma entidade descoberta por acaso durante exploração cirúrgica para HAP, na qual não se detectou o tumor suspeito. Desde então, constatou-se ser uma entidade relativamente freqüente. Além destes, foram descritos o "hiperaldosteronismo supressivo por dexametasona", o "carcinoma", a "secreção ectópica de aldosterona por tumores ovarianos" e outras entidades ainda menos comuns, conforme veremos adiante.

Mais do que uma revisão geral sobre o tema, o enfoque desta apresentação será sobre algumas novidades recentemente reportadas sobre aspectos diagnósticos e terapêuticos do HAP.

\section{Características da Síndrome do HAP}

A perspectiva de se diagnosticar um número maior de casos de HAP numa população de hipertensos "essenciais" é, hoje em dia, muito maior do que se supunha no passado. Nós estamos pessoalmente confirmando esses dados que a literatura vem apresentando nos últimos 7-8 anos.

A hipersecreção de aldosterona resultante de um tumor promove retenção inapropriada de sódio e fluídos e excreção de ions hidrogênio e potássio, resultando em quadro de hipertensão arterial, ao qual podem estar associados hipocalemia e alcalose.

Quando se compara as síndromes de excesso dos principais hormônios produzidos no córtex adrenal aldosterona, andrógenos e cortisol -, vemos que o quadro clínico característico do excesso de aldosterona (ou de outro mineralocorticóide) é relativamente pouco expressivo se comparado à hipersecreção de cortisol ou andrógenos. Enquanto o excesso de aldosterona está associado unicamente com hipertensão arterial e distúrbios hidroeletrolíticos o excesso de cortisol é capaz de produzir manifestações clínicas muito mais amplas, comprometendo inúmeros orgãos e sistemas.

\section{Hiperaldosteronismo Tumoral}

Estatísticas recentes mostram que apenas 50-60\% dos casos de HAP são decorrentes de um "adenoma produtor de aldosterona" (APA). Nos anos 50, acreditava-se que todos os casos resultavam de um "aldosteronoma", mas com o tempo começaram a ser descritos casos de hiperplasia, que nas primeiras revisões pareciam compreender 10 a $20 \%$ dos casos de HAP. Até há pouco, nossos dados apontavam para valores de $40 \%$, mas outros grupos já mostram que a distribuição relativa de casos de hiperplasia e de tumores é equivalente.

Na revisão de mais de 150 casos, compilados até meados da década de 80, no Clinical Study Center do San Francisco General Hospital, na California, os tumores - também denominados de "hiperaldosteronismo tumoral" -, eram responsáveis por $62 \%$ dos casos. Embora mais modesta, nossa estatística do Serviço de Endocrinologia da UNIFESP-Escola Paulista de Medicina, - de cerca de 40 casos nos últimos 10 anos -, mostra que o adenoma adrenocortical corresponde a $50 \%$ dos casos de HAP. Dados mais recentes de outros grupos já apontam para uma maior preponderância de casos de hiperplasia.

$\mathrm{O}$ APA ocorre com maior frequência em mulheres jovens, como no caso apresentado (mulher de 30 anos). Diferente das hiperplasias, onde homens e mulheres são acometidos indistintamente (geralmente numa faixa etária mais avançada), $3 / 4$ dos adenomas acometem mulheres e apenas ${ }^{1} / 4$ os homens.

Interessante é que entre os tumores, existe um subgrupo que apresenta comportamento bioquímico distinto. Enquanto a maioria dos adenomas clássicos não responde a manobras que intervêm no SRA - sistema renina-angiotensina (pela ausência de receptores para angiotensina no tecido neoplásico), um pequeno subgrupo mostra resposta evidente aos estímulos pelo SRA, já que preservam, em número e afinidade, receptores para a angiotensina nas células tumorais. Assim, qualquer manobra que estimule, mesmo que discretamente, os níveis de angiotensina, ou a própria injeção de angiotensina sintética, produz elevação significativa da aldosterona, resposta diversa daquela habitualmente observada nos adenomas típicos. Este subgrupo, denominado de "APA - responsível à angiotensina", corresponde a cerca de $8 \%$ dos casos de HAP, ou cerca de 15 a $18 \%$ dos casos de aldosteronomas.

O "carcinoma adrenal produtor de aldosterona" é uma entidade incomum, responsável por menos de $2 \%$ dos casos de HAP, enquanto "neoplasias com secreção ectópica de aldosterona" são descritas apenas esporadicamente na literatura. Curiosamente, os 
poucos casos descritos eram devidos a tumores ovarianos, não se conhecendo outra fonte de secreção ectópica de aldosterona.

\section{Hiperaldosteronismo Não Tumoral}

Um segundo grupo - caracterizado mais pela ausência de tumor do que propriamente pela presença de hiperplasia -, é denominado de "hiperaldosteronismo não tumoral" ou "pseudo-primário", correspondendo a cerca de $40-50 \%$ dos casos de HAP. A principal entidade deste grupo é o "hiperaldosteronismo idiopático" (IHA, do inglês idiopathic hyperaldosteronism), que mantém essa denominação até hoje por não conhecermos ainda sua etiologia. É provável que não se trate de um problema intrínseco ou primário adrenal, mas talvez de uma doença do receptor de angiotensina.

O "IHA" caracteriza-se pela hipersensibilidade adrenal a manobras que ativam o SRA, o mesmo ocorrendo na vasculatura arterial. Desta maneira, pequenas elevações da concentração de angiotensina produzem por um lado, hiperaldosteronismo e por outro, vasoconstrição. Devido ao envolvimento vascular direto associado à expansão do volume plasmático -, os níveis pressóricos geralmente são mais severos do que nos tumores. Desta maneira, adrenalectomia total bilateral nos casos de hiperplasia, pode produzir melhora, mas não a correção dos níveis pressóricos. Portanto, a maioria desses pacientes, mesmo tendo normalizado seus níveis de potássio, necessitam de medicação antihipertensiva adicional.

Uma outra entidade, descrita por nosso grupo há cerca de 20 anos, é a "hiperplasia adrenal primária", um subgrupo das hiperplasias que corresponde a $6 \%$ dos casos de HAP. Caracteristicamente este subgrupo apresenta comportamento bioquímico autônomo - independente de angiotensina -, semelhante àquele observado no "APA", e diametralmente oposto ao IHA clássico.

Um terceiro subgrupo bastante conhecido, mas muito raro, é o "hiperaldosteronismo supressível por dexametasona", uma condição geneticamente determinada, caracterizada pela expressão anômala da enzima responsável pela produção final de aldosterona (aldosterona sintetase) na zona fasciculada, sob controle do ACTH. Pequenas oscilações fisiológicas do ACTH, aumentando a secreção de aldosterona, produzem a síndrome de hiperaldosteronismo, cujas manifestações podem ser controladas pela supressão com dexametasona ou outro glicocorticóide.

\section{Pseudoaldosteronismo}

Denomina-se "pseudoaldosteronismo" ou "pseudoaldosteronismo primário" a uma síndrome semelhante ao HAP, caracterizada por hiperatividade mineralocorticóide, hipertensão arterial, hipocalemia e renina suprimida, mas com aldosterona também suprimida. Nesta situação o responsável é um outro mineralocorticóide, e o segundo deles em importância é a deoxicorticosterona (DOC), que se encontra quase sempre elevada nesta situação. Embora outros mineralocorticóides possam estar envolvidos em síndromes mais raras, a imensa maioria das situações de "pseudoaldosteronismo" se deve à presença de excesso de DOC (hiperDOCismo ou hiperdeoxicorticosteronismo).

Não se deve confundir este termo com outro ocasionalmente empregado nesta disciplina, o "hiperaldosteronismo pseudo-primário", que alguns autores escolheram como sinônimo de hiperaldosteronismo não tumoral ou por hiperplasia (IHA).

\section{Evolução Natural e Diagnóstico Precoce do HAP}

É importante conhecer, do ponto de vista fisiopatológico, como evoluem os casos de HAP. Num determinado momento (tempo zero, ou início da história natural de um tumor ou hiperplasia produtores de aldosterona) a concentração de aldosterona começa a se elevar, e continua por um período de dias/semanas, passando para níveis normais altos, e depois de meses/anos, para níveis moderada ou já significativamente elevados (figura 2). O que ocorre neste período de tempo é, fundamentalmente, uma retenção continuada de sódio e de fluidos, promovida pelos níveis inapropriadamente elevados de aldosterona, que vão gradualmente expandindo o volume do líquido extracelular e o volume plasmático. Com isso, baro e quimiorreceptores das arteríolas aferentes do glomérulo são ativados e as células do aparelho juxtaglomerular prontamente informadas a reduzir a liberação de renina. Desta maneira, após alguns dias/semanas, a concentração (ou atividade plasmática de) renina já se encontra baixa e, ao cabo de vários meses, encontra-se invariavelmente suprimida. Neste período, e através deste mecanismo, a hipertensão possivelmente já está instalada.

Este fenômeno pode ser facilmente observado em animais de experimentação pela administração continuada de aldosterona e comprovado em portadores de HAP, nos quais a descontinuação autorizada do tratamento com espironolactona (Aldactone ${ }^{\circledR}$ ) - que revertera completamente as manifestações clínicas da doença -, permite a reinstalação gradual do quadro.

O potássio, por ser um íon predominantemente intracelular, tem uma reserva enorme, sendo capaz de manter níveis sanguíneos normais por tempo relativamente maior. Mesmo após semanas/meses, sua concentração sérica pode ainda estar na faixa normal. Para 


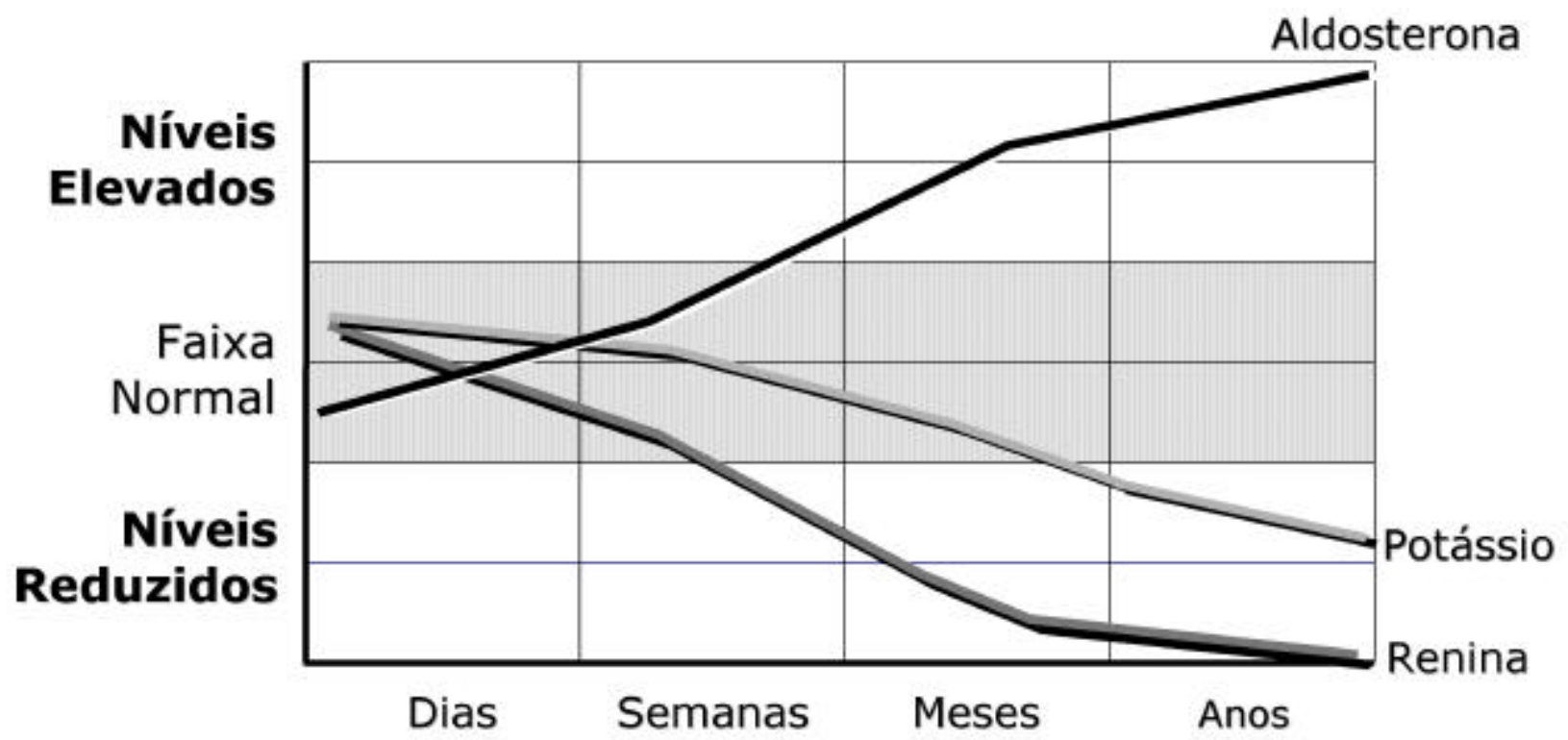

Figura 2: Diagrama da história natural e evolução clínica do hiperaldosteronismo primário.

que hipocalemia clínica e manifesta possa efetivamente ser notada, decorre um tempo mais longo - geralmente meses/anos -, do que a expansão de volume e a supressão da renina. Presumo que um paciente que apresente no diagnóstico níveis de potássio de 1,7 a 2 $\mathrm{meq} / \mathrm{L}$, tenha um tempo de evolução da doença de muitos anos, podendo ter sido diagnosticado bem antes. Os sinais e sintomas resultantes de hipocalemia, como parestesias, cãimbras, fraqueza muscular, paralisia flácida, poliúria e arritmias cardíacas, podem estar ausentes, ou então se manifestar de maneira evidente quando a hipocalemia é severa, como no caso da paciente apresentada.

\section{Diagnóstico Laboratorial do HAP}

Bioquimicamente, o HAP é uma combinação clássica de aldosterona elevada com renina reduzida. Os níveis de aldosterona (tanto no sangue como na urina) podem estar desde discretamente elevados, ou mesmo na faixa superior da normalidade, até muito altos, e os de renina, geralmente reduzidos, mas frequentemente suprimidos. Portanto, quando determinados concomitantemente no HAP, estão sempre em direções opostas.

O IHA (hiperplasia adrenal) é o subgrupo de HAP que tende a ter os níveis de aldosterona mais modestamente elevados, muito frequentemente na faixa normal, mas com renina baixa, embora não necessariamente suprimida. Por isto, este subgrupo escapa mais facilmente ao diagnóstico, até porque valores de aldosterona na faixa normal alta (12 a $15 \mathrm{ng} / \mathrm{dL})$, ou reninas na faixa normal baixa $(0,2$ a $0,4 \mathrm{ng} / \mathrm{mL} / \mathrm{h})$, são frequente e infelizmente pouco valorizados para o diagnóstico.

\section{O Valor do Potássio no Diagnóstico do HAP}

Hipocalemia sempre foi a marca registrada do HAP. Entretanto, níveis séricos normais de potássio não autorizam a "exclusão" do diagnóstico. Nas grande séries de casos de HAP, publicadas há 25 ou 30 anos, os níveis de potássio mostravam-se quase sempre baixos, frequentemente na faixa de 2,0 a $3,2 \mathrm{meq} / \mathrm{L}$, e os de sódio, habitualmente na faixa normal alta, entre $142 \mathrm{e}$ $145 \mathrm{meq} / \mathrm{L}$. Estes são os casos "clássicos", idênticos ao da paciente apresentada, que tinha níveis de 1,7 - 2,0 e $145 \mathrm{meq} / \mathrm{L}$, respectivamente.

Vale salientar, entretanto, que naquelas séries sempre existiu uma sub-população de pacientes com níveis de potássio normais, especialmente nos casos de hiperplasia, que correspondia a menos de $10 \%$ dos casos. Além disso, normocalemia pode ser observada no HAP, devido a flutuações na concentração sérica de potássio, à presença de comprometimento da função renal e, principalmente, na eventualidade do paciente estar ingerindo dieta com restrição de sódio e/ou com elevado teor de sais de potássio.

Graças ao interesse na detecção precoce e aos procedimentos diagnósticos mais sensíveis, que não levam necessariamente em conta a presença de hipocalemia, podemos identificar, atualmente, um número muito maior de pacientes normocalêmicos com diagnóstico comprovado de HAP, provavelmente atingindo mais de $50 \%$ dos casos detectados. 
Além disso, estudos de rastreamento de HAP em populações de ambulatórios gerais, não necessariamente de hipertensos, tem possibilitado a identificação precoce de pacientes não somente normocalêmicos, mas também normotensos!

Há quase 20 anos, Emmanuel Bravo, da Cleveland Clinic, em Cleveland, Ohio, mostrava que a prevalência de hipocalemia espontânea em casos de HAP era de 80 a $90 \%$, já que este era o "marcador" da doença. Nos restantes $10-20 \%$ dos casos, nos quais os níveis de potássio eram normais, "suspeitos" ou fronteiriços (pacientes sob dieta hipo ou assódica ou em uso de reposição de potássio), utilizava-se uma manobra para provocar hipocalemia administrando ao paciente uma sobrecarga oral de sódio, através de dieta hipercloretada. Na presença de excesso de aldosterona, a adição por aguns dias de 6 a $10 \mathrm{~g} / \mathrm{dia}$ de $\mathrm{NaCl}$ a uma dieta normal, era suficiente para aumentar a excreção urinária de potássio e provocar hipocalemia em pelo menos metade daqueles casos.

Ainda segundo dados de Bravo, a presença de hipocalemia espontânea em pacientes hipertensos sistêmicos tem sensibilidade de $75 \%$ e especificidade de $95 \%$, na identificação de HAP, afastado o uso de diuréticos e outros fatores iatrogênicos. A hipocalemia provocada pela sobrecarga de sódio, melhora a sensibilidade diagnóstica para $85 \%$, elevando ainda mais a especificidade para $98 \%$.

Aqueles que se utilizam da dosagem de potássio para investigar HAP devem estar alertas para o fato de que em significativa parcela de casos, esses níveis não estão necessariamente reduzidos, ou então, situam-se numa faixa que habitualmente não chama a atenção, entre 3,4 e $3,7 \mathrm{meq} / \mathrm{L}$. É habitual o clínico mostrar-se desatento a esses níveis discretos de hipocalemia, mesmo sabendo que todas as possíveis causas de erro na dosagem do potássio (analíticas e, principalmente, pré-analíticas, como garroteamento do braço, hemólise da amostra, etc), superstimam sua concentração. Muitos colegas me consultam a respeito do diagnóstico de HAP apenas quando encontram valores de potássio sérico na faixa extrema de 1,5 a 2,0 meq/L. Independente de desatenção ou simples desconhecimento, é importante ressaltar e valorizar esta observação do grau de tolerância do organismo à depleção de potássio, expressa por estes valores séricos críticos. Diferente do que ocorre na depleção aguda de potássio, quando concentrações séricas nem tão acentuadas resultam em arritmia e parada cardíaca, níveis de 1,5 a 1,7 meq/L são vistos esporadicamente (e razoavelmente tolerados) em pacientes com HAP, uma idiosincrasia justificada pelo longo período de depleção.

\section{A Adição da Renina no Diagnóstico do HAP}

Outro parâmetro que passou a ser investigado posteriormente na evolução natural do hiperaldosteronismo foi o SRA. Na época da identificação do HAP, conhecia-se pouco sobre o SRA-aldosterona e Conn ainda não tinha disponível nenhum ensaio para a dosagem de renina. Quase uma década depois é que a investigação do HAP passou a englobar a determinação da atividade plasmática da renina (APR, através de radioimunoensaio para dosagem da angiotensina I gerada em condições pré-determinadas), quando se documentou que a renina estava sistematicamente suprimida, em decorrência da conhecida e evidente expansão do volume do líquido extracelular e do volume plasmático.

Além da dosagem basal da APR, manobras dinâmicas de estímulo permitiram alguma perspectiva na diferenciação entre as duas principais etiologias do HAP, tumoral (APA) e não tumoral (IHA).

Dentre os vários testes de estímulo propostos (dieta hipo ou assódica por vários dias, administração oral ou IV de furosemida e estímulo postural) este último é o mais prático, simples e eficiente. Nos adenomas a APR encontra-se suprimida e consistentemente não responsível ao se assumir a posição ereta por 2 hs. Este teste pode ser feito com o indivíduo deambulando ou não, após uma noite deitado ou, de maneira mais prática, após 30 a $45 \mathrm{~min}$ recostado e com as pernas distantes do chão. Nos casos de IHA, a APR encontra-se baixa, mas não suprimida, e muitas vezes apresenta algum esboço de resposta ao de estímulo postural.

É importante estar atento para a existência, entre pacientes "hipertensos essenciais com renina baixa", de um subgrupo que possa ser diagnosticado como HAP. Em nossa experiência esta sub-população pode chegar a $20 \%$ dos casos. As manifestaçôes clínicas tendem a ser mais discretas, mas com o mesmo padrão bioquímico de renina baixa ou mesmo suprimida, em contraste com os "hipertensos essenciais com renina normal". Tanto os níveis de potássio como os de aldosterona (plasmática ou urinária) não estão necessariamente muito alterados, embora a relação aldosterona:renina esteja elevada.

O ensaio para dosegem da APR, embora hoje disponível de rotina, tem inúmeras causas de erro, geralmente no processamento pré-analítico, dificultando muitas vezes sua interpretação correta. Um radioimunoensaio recente dosa diretamente a enzima (renina), dispensando a relativa complexidade da determinação da APR. Maior experiência ainda é necessária para avaliar sua utilidade no diagnóstico do HAP.

\section{A Relação Aldosterona: Renina Plasmática na}




\section{Identificação de Casos de HAP}

Uma vez que no HAP os níveis plasmáticos de aldosterona e de renina movem-se em direções opostas, parece razoável se empregar um índice que combine o poder diagnóstico de ambos os parâmetros para discriminar com maior acurácia casos até insuspeitos da doença. Portanto, a relação aldosterona-renina (A:APR) - a primeira medida $\mathrm{em} \mathrm{ng} / \mathrm{dL}$ e a segunda $\mathrm{em} \mathrm{ng} / \mathrm{mL} / \mathrm{h}$-, tornou-se, mais recentemente, um importante instrumento diagnóstico no rastreamento do HAP.

Entretanto, este artifício não é nenhuma novidade, tendo sido publicado há anos atrás, mas esquecido ou deixado de lado por razóes desconhecidas, talvez envolvendo aspectos de praticidade ou custo. É evidente que desde que se disponha da dosagem plasmática concomitante de aldosterona e APR, basta uma simples conta de dividir. Seu emprego, entretanto, passou a ser rotineiro apenas nessa última década, quando a detecção de casos de HAP elevou-se numa frequência assustadora.

As dosagens para se determinar a relação A:APR são feitas numa amostra matinal de sangue colhida com o indivíduo em pé, em atividade normal, 2 a 4hs após ter-se levantado e durante uma visita ambulatorial de rotina. Não há necessidade de qualquer preparo prévio, jejum, ou mesmo interrupção de medicamentos.

Nestas condições, quando se encontra uma relação A:APR menor do que 20, o diagnóstico de HAP é improvável e acima de 20, suspeito. Valores maiores do que 25 tornam o diagnóstico fortemente suspeito, maiores do que 30 provável e acima de 40 , quase certo. Desta maneira, pode-se eleger qualquer ponto de corte (cutoff) acima de 20 para a relação A:APR: o teste ganha grande sensibilidade quando usamos um cutoff mais baixo, 20 ou próximo dele; ao contrário, ganha em especificidade, se escolhemos um cutoff próximo de 40.

Não se deve esquecer que para qualquer teste de rastreamento de doenças, habitualmente se opta por um valor de corte associado a alta sensibilidade, sacrificando-se, evidentemente, a especificidade. Por exemplo, a escolha de um cutoff de 20 , durante um virtual screening para HAP num ambulatório de hipertensão, cardiologia ou nefrologia, permite com grande chance a detecção de todos os possíveis casos de HAP, embora estejamos incluindo um número significativo de falso-positivos, pela perda de especificidade. Para que o diagnóstico de HAP seja efetivamente descartado nestes falso-positivos, deveremos empregar outros testes e procedimentos - habitualmente com o paciente internado -, que seriam trabalhosos e forçosamente mais onerosos. Por outro lado, ao escolher um valor de corte que permita alta especificidade (40 ou mais, por exemplo), corremos o risco de não diagnosticar uma parcela de casos verdadeiros de HAP, aqui classificados como falso-negativos.

O melhor valor de corte, portanto, é aquele que permita combinar a melhor (mais alta) sensibilidade com a melhor (mais alta) especificidade. Este ponto pode ser determinado através de curvas ROC (receiveroperator characteristics), estudando-se extensamente uma amostra populacional significativa.

Existem alguns poucos e pequenos fatores interferentes na interpretação da relação A:APR, favorecendo resultados falso-positivos ou falso-negativos. Por exemplo, a idade avançada, a insuficiência renal e o uso de beta-bloqueadores, tendem a produzir resultados falso-positivos, fundamentalmente por conta dos níveis mais baixos de renina encontrados nestas situações; na maioria das vezes, entretanto, a concentração plasmática de aldosterona acompanha os níveis de renina, afetando pouco a relação A:APR. Resultados falso-negativos podem ser encontrados em pacientes com HAP em uso crônico de diuréticos ou de antagonistas de canal de cálcio, especialmente os dihidrodipiridínicos. Os primeiros podem elevar significativamente a APR e os últimos, reduzir a secreção de aldosterona. Em presença de hiperaldosteronismo, a relação A:APR mostra-se bastante confiável com o uso de prazosin, hidralazina ou inibidores da ECA, medicamentos que podem, portanto, ser mantidos, enquanto os demais mencionados talvez mereçam ser interrompidos para investigação posterior.

Na figura 3, estão representados os valores individuais da relação $\mathrm{A}: \mathrm{APR}$, determinados retrospectivamente de estudos anteriores de nosso grupo. Vê-se, nos casos de APA, que a média dos dados foi de $230 \pm 180$, mesmo valor do caso da paciente apresentada (232); os valores mais baixos encontrados em APA estão na faixa de 40, e os mais elevados acima de 400, atingindo muitas vezes valores acima de 1000; no IHA, os valores tendem a ser mais baixos, $64 \pm 50$, variando de 20 a 110.

Interessante notar que nos casos conhecidos e publicados de hipertensão essencial, usados como controles de HAP, a média dos valores é baixa, mas observam-se alguns poucos pacientes com valores mais elevados, na faixa de HAP, que passaram desapercebidos na ocasião, mas hoje certamente teriam sido diagnosticados como HAP. Vê-se, também, que indivíduos controles normais tem valores da relação de $9 \pm 6$, não ultrapassando 15.

Prevalência de HAP - Porque se Pensa Tão Pouco 


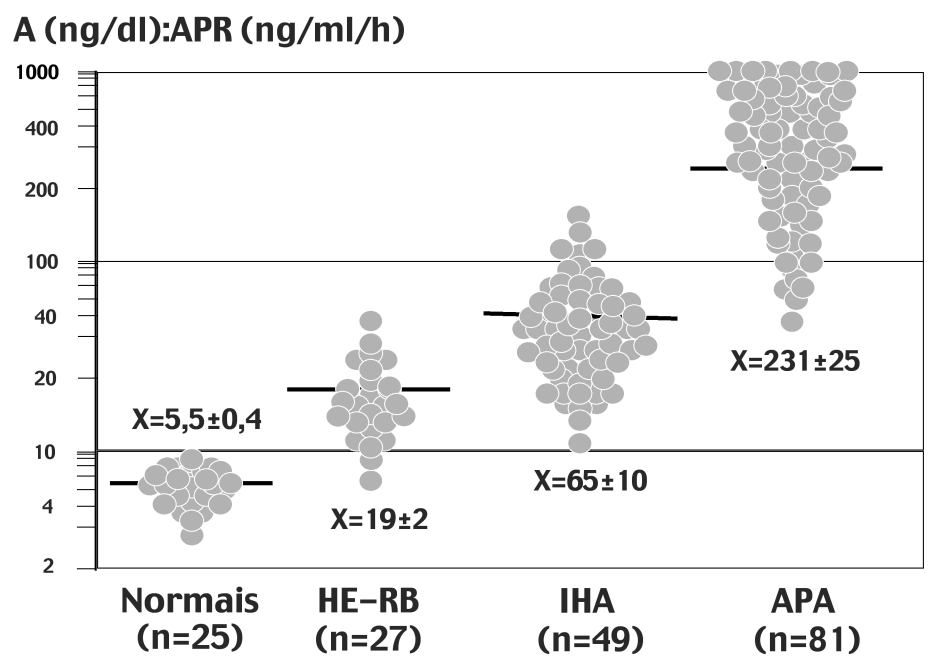

Figura 3. Valores individuais da relação aldosterona (em $\mathrm{ng} / \mathrm{dL}$ ):renina (em $\mathrm{ng} / \mathrm{mL} / \mathrm{h}$ ) em pacientes com hiperaldosteronismo primário por adenoma (APA) ou hiperplasia (IHA) e com hipertensão essencial com renina baixa (HERB) e voluntários normais não hipertensos.

\section{no Diagnóstico?}

Se, numa população específica de hipertensos, considerarmos o diagnóstico de HAP apenas quando o conjunto de sinais e sintomas estiver evidente, encontraremos uma prevalência provavelmente da ordem de 0,1 a $0,5 \%$. Estes dados estão disponíveis em qualquer livro de texto sobre o assunto.

Se pesquisarmos sistematicamente os níveis de potássio em todo paciente hipertenso, independente de sintomas, e valorizarmos o achado de hipocalemia leve ou moderada, e mesmo níveis normais baixos de potássio, a detecção de HAP dobra ou triplica, elevando a prevalência para a faixa de 0,5 a $2 \%$. Este tem sido o procedimento habitual de rastreamento bioquímico para HAP preconizado pela maioria dos Serviços de Hipertensão, desde há muitos anos. A inclusão da determinação de APR no screening para HAP, parece elevar os dados de prevalência para algo ao redor de 2 a $5 \%$ dos hipertensos, quando se encontram valores suprimidos.

Parece óbvio que se passarmos a investigar a possibilidade de HAP em populaçôes de hipertensos (e mesmo de não hipertensos) por meio de um teste ou procedimento ainda mais sensível, por exemplo a determinação da relação A:APR, a prevalência da doença seria, como parece ser, muito maior, provavelmente na faixa de 5 a $10 \%$.

Considerando que os casos clínicamente manifestos sejam apenas a ponta de um iceberg, testes de rastreamento extremamente sensíveis, como por exemplo a determinação do volume plasmático, poderiam detectar um número ainda maior de casos. Realisticamente, entretanto, há que se levar em conta a significativa perda de especificidade, a complexidade do procedimento e todo o custo envolvido no processo.

$\mathrm{O}$ quadro l. mostra estudos de rastreamento e prevalência de HAP realizados em amostras da população geral, em ambulatórios de hipertensos e em centros de saúde. Os primeiros estudos, englobando amostras de 700 a 4.000 indivíduos hipertensos, eram datados de 1976, 1981 e 1987, antes, portanto, da utilização da relação A:APR, e quando apenas se utilizava a hipocalemia como "identificador" do HAP. Nestes estudos, a prevalência de HAP não ultrapassou $0,2 \%$. Entretanto, desde que se passou a utilizar a relação A:APR, de 1993 até os dias de hoje, a prevalência de HAP vem aumentando para índices na faixa de $8,1 \%$ a $13,4 \%$. Embora pareça difícil acreditar em prevalências tão altas, pessoalmente tenho encontrado números muito maiores do que antes imaginava. Um estudo prospectivo colaborativo multicêntrico e sistematizado incluindo indivíduos do norte ao sul do país poderia trazer uma resposta a esta questão, pelo menos no Brasil.

Dois grandes centros de estudos em hipertensão, a Mayo Clinic, em Rochester, Minesotta, EUA (William Young Jr) e o Hospital Greensleaves, em Brisbane, Australia (Richard Gordon), reportaram dados interessantes. No primeiro, a média de pacientes diagnosticados com HAP, de 1960 a 1991, era de 12 pacientes por ano; entre 1992 e 1999, quando passaram a utilizar a relação A:APR, a média anual 
Quadro 1. Prevalência de hiperaldosteronsimo primário (HAP) nos últimos 25 anos, segundo o método de rastreamento.

\begin{tabular}{lrcrrrrr}
\hline População estudada & $\mathbf{n}=$ & Método & Cutoff & Prevalência & Ano & Autor & Referência \\
\hline Geral & 689 & HipoK+ & & $0,1 \%$ & 1976 & Berglund & 3 \\
Hipertensos & 1.000 & HipoK+ & & $0,1 \%$ & 1981 & Danielson & 10 \\
Hipertensos & 3.783 & HipoK+ & & $0,2 \%$ & 1987 & Sinclair & 32 \\
Voluntários Hipertensos & 785 & Aldo:APR & & $12,0 \%$ & 1993 & Gordon & 19 \\
Hipertensos & 199 & Aldo:APR & $>30$ & $8,5 \%$ & 1994 & Gordon & 18 \\
Hipertensos & 110 & Aldo:APR & $>30$ & $11,8 \%$ & 1996 & Widimsky & 40 \\
Hipertensos & 574 & Aldo:APR & & $13,0 \%$ & 1998 & Rossi & 31 \\
Hipertensos Não Selecionados & 495 & Aldo:APR & $>27$ & $8,1 \%$ & 1998 & Lim & 23 \\
Hipertensos Não Selecionados & 125 & Aldo:APR & $>27$ & $13,4 \%$ & 1999 & Lim & 24 \\
Hipertensos & 305 & Aldo:APR & $>25$ & $9,5 \%$ & 2000 & Fardella & 12 \\
Normotensos & 205 & Aldo:APR & $>25$ & $1,5 \%$ & 2000 & Fardella & 12 \\
Hipertensos & 350 & Aldo:APR & $>20$ & $5,1 \%$ & 2000 & Loh & 26 \\
\hline
\end{tabular}

elevou-se 10 vezes. No segundo, o número de casos comprovados de HAP, de 1983 a 1990, era menor do que 10 por ano, mas de 1991 a 1999, com o uso da relação A:APR, elevou-se para 90 pacientes/ano.

A relação A:APR deverá ser interpretada com precaução quando o valores basais de aldosterona plasmática estiverem abaixo de $12 \mathrm{ng} / \mathrm{dL}$. Adicionalmente, quando os valores de APR estiverem muito baixos ou suprimidos $(<0,1 \mathrm{ng} / \mathrm{mL} / \mathrm{h}$, na maioria dos ensaios), recomenda-se que sejam corrigidos para $0,2 \mathrm{ng} / \mathrm{mL} / \mathrm{h}$, permitindo maior confiança na interpretação da relação. Habitualmente, os níveis suprimidos de APR têm, isoladamente, maior poder diagnóstico (valor preditivo positivo) do que aldosterona elevada.

Outras etiologias de hipertensão arterial, mesmo com hipocalemia, podem apresentar valores da relação A:APR normais e, assim, virtualmente excluir HAP. A relação A:APR encontra-se na faixa normal, ao redor de 10, em situações onde aldosterona e APR estão ambas elevadas, como na hipertensão renovascular, tumores secretores de renina, malignização de hipertensão, uso de diuréticos, etc. Por outro lado, APR baixa ou suprimida com aldosterona também baixa, ocorrem em casos de pseudoaldosteronismo primário (excesso de outro mineralocorticóide), insuficiência renal com hipoaldosteronismo hiporreninêmico (acidose tubular renal tipo IV) e em outras entidades menos comuns.

\section{Confirmação do Diagnóstico de HAP}

Uma vez suspeitado pelo encontro de hipertensão, com ou sem hipocalemia, renina suprimida e/ou a relação A:APR elevada, o diagnóstico de HAP necessita de confirmação. Fundamental, neste ponto, é a caracterização da autonomia do excesso de aldosterona através de testes de supressão, conforme realizado no caso apresentado.
Podem ser utilizados para este fim manobras como a infusão de solução salina, ingestão de dieta hipercloretada por alguns dias, ou o emprego de outro mineralocorticóide, de maneira análoga ao que se faz na síndrome de Cushing, quando se administra dexametasona para suprimir os níveis de cortisol. Neste caso, podemos utilizar o acetato de deoxicorticosterona (DOCA, 10mg IM a cada $12 \mathrm{hs}$ ) ou a fludrocortisona $(0,2 \mathrm{mg} \mathrm{VO}$ a cada $12 \mathrm{hs})$, ambos durante 3 dias. Entretanto, o teste mais simples, menos invasivo e de menor risco (por exemplo, para um paciente hipertenso severo e cardiopata), consiste na ingestão por 3 a 5 dias de uma dieta rica em sódio, com cerca de 6 a $10 \mathrm{~g}$ de $\mathrm{NaCl}$ por dia. A observação de eventual queda $(>50 \%)$ dos níveis plasmáticos e/ou urinários de aldosterona nesse período exclui o diagnóstico de HAP. Para a maioria dos autores, manutenção da aldosterona urinária em níveis $>12 \mu \mathrm{g} / 24$ hs após supressão, estabelece o diagnóstico de certeza de HAP.

\section{Como Diferenciar Tumor (APA) de Hiperplasia (IHA)}

Uma vez estabelecido o diagnóstico sindrômico, o passo seguinte é a diferenciação entre tumor (APA) e hiperplasia (IHA) - as causas mais comuns de HAP -, levando-se em conta que há $50 \%$ de chance para cada uma delas.

Além de prevalências distintas por sexo e idade, outras diferenças bioquímicas entre APA e IHA permitem estabeler um diagnóstico diferencial confiável, posteriormente complementado pelos procedimentos de imagem. As alterações bioquímicas são mais pronunciadas no adenoma do que na hiperplasia, como aldosterona basal mais elevada $(>25 \mathrm{ng} / \mathrm{dL}$ no APA e $<25$ no IHA), bem como dos esteróides precursores DOC, 18-hidroxicorticosterona, 18-oxo- e 18-hidroxicortisol. 
Entretanto, melhor definição diagnóstica baseia-se na evidência de que nos tumores existe ausência ou redução do número e afinidade de receptores de angiotensina II e, na hiperplasia, aumento. Caracteriza-se assim, no APA e no IHA, respectivamente resistência e hipersensibilidade aos procedimentos que manipulam o SRA, como o teste da postura, a dieta hipossódica, a administração de diuréticos e de espironolactona (SPL). Em todos eles, a aldosterona plasmática não apresenta resposta no tumor, mas eleva-se acentuadamente na hiperplasia.

Assim, à semelhança do que ocorre no indivíduo normal, pacientes com IHA caracteristicamente elevam seus níveis de aldosterona plasmática 2 a 4 vezes quando assumem a posição ereta por $2 \mathrm{a} 4 \mathrm{~h}$. No APA, ao contrário, embora os níveis de aldosterona basal sejam muito mais elevados, não ocorre elevação adicional, havendo até mesmo queda dos valores. Isto se dá pela ausência de receptores para angiotensina $\mathrm{e}$ pelo fato da APR estar suprimida nos adenomas. As exceções à regra, - elevação da aldosterona em alguns tumores e ausência de resposta em certos casos de hiperplasia -, caracterizam os casos atípicos, respectivamente o "APA responsível à angiotensina" e a "hiperplasia adrenal primária”.

Considera-se resposta normal ao teste da postura, conforme observada em indivíduos normais e no IHA, um incremento de aldosterona maior do $30 \%$ em relação ao valor basal; no APA, eventuais elevações são consistentemente menores do que $30 \%$. Este valor de corte foi estabelecido por nosso grupo, pela análise de curvas ROC (receiver operator characteristic), nas quais procura-se determinar o ponto de corte que tenha a melhor especificidade e sensibilidade do teste.

Da mesma maneira, o teste terapêutico com SPL permite que se avalie o comportamento da aldosterona plasmática e, principalmente, urinária. num período de tempo mais longo. Após semanas ou meses do uso de SPL, tendo-se eliminado a sobrecarga de sódio e fluidos, obtém-se a normalização dos níveis de PA, potássio e APR em casos de HAP. Mesmo assim, tanto a concentração plasmática como a urinária de aldosterona não se alteram no APA, enquanto elevam-se substancialmente no IHA, conforme a explicação anterior.

Hoje em dia, dada a facilidade e ampla disponibilidade dos procedimentos de imagem, não se costuma aguardar pelos resultados de testes bioquímicos para estabelecer o diagnóstico de HAP, partindo-se prontamente para a investigação radiológica. Trata-se de uma inversão de princípios básicos da investigação clínica, e da própria índole do endocrinologista, apenas justificada pelo respeito a ansiedade do médico e do paciente.
Deve-se ter em mente, entretanto, que resultados aparentemente paradoxais podem ocorrer e confundir o cenário como, por exemplo, o encontro de uma lesão em uma das adrenais em presença de resultados bioquímicos sugestíveis de hiperplasia; pode-se tratar tanto de um adenoma (APA) responsível à angiotensina, como de uma IHA clássica com presença de um nódulo dominante, ou único, e mesmo de um incidentaloma.

Deve ser lembrado que as hiperplasias podem ser uni ou multinodulares, micro ou macronodulares, e mesmo ocorrer com adrenais de aspecto normal à imagem.

\section{Opções Terapêuticas no HAP}

A abordagem terapêutica do HAP é cirúrgica ou medicamentosa, dependendo do diagnóstico do subtipo. A opção cirúrgica é reservada para os tumores adrenais (adrenalectomia unilateral).e para os casos específicos de "hiperplasia adrenal primária" (adrenalectomia parcial ou subtotal). Hoje em dia, cada vez mais se emprega a via videolaparoscópica, que nas mãos de cirurgiões experientes apresenta mínima morbi-mortalidade peri-operatória.

O tratamento farmacológico, contínuo ou preparatório para a cirurgia, é baseado no uso de espironolactona (SPL), um agente antagonista competitivo específico do receptor de aldosterona. Nos casos de HAP supressível por glicocorticóides, o tratamento consiste na administração de dexametasona.

A dose habitualmente empregada de SPL (Aldactone ${ }^{\circ}$, Searle) varia de 100 a $400 \mathrm{mg} / \mathrm{dia}$, usada apenas uma vez ao dia, que é a nossa preferência, mas podendo ser fracionada em duas vezes. Nos casos de intolerância gastrointestinal ao produto, e especialmente quando do uso prolongado em homens, por causa de seus efeitos anti-androgênicos adicionais, produzindo ginecomastia, redução da libido, etc, podem ser utilizados outros agentes diuréticos poupadores de potássio. A amilorida é a melhor alternativa à SPL, mas não é comercializada no Brasil, como produto isolado. Pode ser obtida no mercado norte-americano sob o nome comercial de Midamor ${ }^{\circledR}$ (MS\&D), e é empregada em doses de 10 a 40 $\mathrm{mg} /$ dia. Seu mecanismo de ação é distinto, agindo nos canais de cálcio e sódio não mineralocorticóidessensíveis, produzindo natriurese sem expoliação de potássio. Outra alternativa, menos eficiente, é o triantereno, um produto disponível há anos, mas também não encontrado no mercado brasileiro, a não ser em combinação. Disponível no mercado norte-americano (Dyrenium ${ }^{\circledR}, S K \& B$ ), pode ser usado em doses de 50 a $200 \mathrm{mg} /$ dia. 
Em lugar dos diuréticos mencionados, podemos utilizar bloqueadores dos canais de cálcio e inibidores da enzima de conversão. Embora sejam menos efetivos, funcionam adequadamente para o controle da pressão arterial, mas não normalizam os níveis de potássio.

Alguns derivados da progesterona, à semelhança da SPL, têm sido pesquisados, visando aumentar a potência anti-mineralocorticóide e reduzir os efeitos anti-androgênicos. Assim, o canrenoato de potássio, com poucos dados disponíveis, não mostrou-se superior à SPL e, mais recentemente, a eplerenona, ainda em fase de investigação clínica, parece promissora, pois é um antagonista da aldosterona eficiente com menor atividade anti-androgênica que a SPL e, portanto, recomendável ao homem e mesmo à mulher, evitando a ocorrência de irregularidades menstruais.

A maioria dos estudos com Aldactone ${ }^{\circledR}$ utiliza doses altas, de $400 \mathrm{mg} /$ dia; nós utilizamos 200 a $300 \mathrm{mg}$, que parecem suficientes, embora alguns casos possam precisar de doses maiores. A redução da PA é significativa e o efeito hipotensivo é muito maior nos casos de HAP e na hipertensão com renina baixa, do que em qualquer outro tipo de hipertensão.

A relação A:APR elevada parece ser preditiva da resposta hipotensora da SPL, e uma única medida pode ser a base para individualizar o manuseio da hipertensão. Estudos epidemiológicos recentes sugerem que o uso de diuréticos não poupadores de potássio em hipertensos é um fator de risco para morte súbita cardíaca. Entretanto, em casos de HAP mais resistentes ao tratamento farmacológico convencional, podemos associar à SPL, doses pequenas de diuréticos tiazídicos, potencializando seu efeito sobre a PA.

Alguns estudos comprovam que o tratamento farmacológico de longa duração em pacientes com HAP é uma alternativa viável para controlar a PA e a hipocalemia, em lugar da cirurgia, especialmente em se tratando de pacientes com grande risco cirúrgico.

\section{Evitando o Hipoaldosteronismo Pós-Cirúrgico}

O emprego de SPL como parte do tratamento do HAP visa a normalização da PA e dos níveis de potássio e APR para, então, recomendar cirurgia nos casos de APA. Isto é feito não somente para propiciar ao paciente menor risco cirúrgico, como para permitir a total recuperação da zona glomerulosa contralateral ao adenoma, certamente atrofiada. Como esta recuperação funcional pode levar algum tempo, recomendamos sempre que o paciente seja tratado por vários meses com SPL, aguardando a completa normalização dos níveis de potássio e APR, agentes tróficos da zona glomerulosa. Caso contrário, poderemos ser surpreendidos, dias após a adrenalectomia, com um quadro, por vezes grave, de hipoaldosteronismo, que necessitará de tratamento de reposição com fludrocortisona por períodos variáveis. No caso da paciente aqui apresentada, pode ter ocorrido provavelmente um hipoaldosteronismo relativo, já que, depois de operada apresentou níveis reduzidos de aldosterona. Este comportamento é em tudo semelhante à síndrome de Cushing por adenoma adrenocortical produtor de cortisol. A desatenção com a recuperação contralateral pode resultar em quadros graves de insuficiência glicocorticóide.

\section{DISCUSSÃO ABERTA}

\section{Dr. Alexandre Bitencourt Rosendo (médico resi- dente, Serviço de Endocrinologia do HC-FMUSP)}

Qual o papel da cintilografia adrenal no diagnóstico diferencial do hiperaldosteronismo primário?

\section{Prof. Dr. Claudio Elias Kater (Professor Adjunto de Medicina, Disciplina de Endocrinologia da Uni- versidade Federal de São Paulo)}

Os procedimentos da Medicina Nuclear não podem jamais ser desprezados, embora não tenham grande especificidade. Não dispomos, na verdade, de um fármaco com especificidade suficiente para detectar um tumor produtor de aldosterona. Existe, além disso, um arsenal de outros procedimentos de imagem, o que torna a cintilografia adrenal praticamente dispensável. Por outro lado, não tenho maior experiência com a cintigrafia. No início dos anos 80, acompanhei na UC San Francisco, alguns estudos com o agente NP-59, um derivado sintético do colesterol com melhor resolução cintigráfica. Ele era utilizado durante supressão do ACTH com dexametasona, permitindo o mapeamento de tumores, mas, em geral, apenas aqueles com mais de $2 \mathrm{~cm}$ de diâmetro, inviabilizando a detecção de parcela significativa dos aldosteronomas.

\section{Dr. Luiz Roberto Salgado (médico assistente, Serviço de Endocrinologia e Metabologia do HC- FMUSP)}

Você acha necessário confirmar o diagnóstico de hiperaldosteronismo com o teste de infusão salina em um paciente com relação aldosterona:renina maior do que 40 ?

\section{Prof. Dr. Claudio Elias Kater}

Estamos, no momento, conduzindo um grande estudo colaborativo para avaliar a variabilidade da relação aldosterona:renina na população geral e, em particular, em indivíduos hipertensos. Nosso objetivo é determi- 
nar qual o melhor nível de corte (cutoff) a partir do qual podemos dispensar outros procedimentos diagnósticos. Existe, obviamente, uma relação custo-benefício a ser considerada, já que muitos indivíduos suspeitos da doença necessitam de internação para procedimentos diagnósticos, como a supressão com salina, que por sua vez não é isenta de riscos. Assim, quanto maior o nível de corte estipulado, por exemplo 40, maior a chance de poder dispensar outros procedimentos. Por outro lado, há redução de sensibilidade, correndo-se o risco de perder alguns pacientes com manifestações bioquímicas muito discretas da doença. Como não temos ainda esse dado, não sabemos as porcentagens de resultados falso-positivos e falso-negativos com os vários níveis de cutoff. Por isso, escolhemos arbritariamente investigar todos os pacientes que tenham relação aldosterona:renina igual ou maior do que 25. Mesmo aqueles com valores bem mais elevados serão, inicialmente, investigados por completo, a única maneira de se detectar resultados falso-positivos. Corremos um pequeno risco, evidentemente, com os falso-negativos, aqueles portadores de HAP com valores da relação abaixo de 25 , mas esta parcela deve ser desprezível.

\section{Dr. Luiz Roberto Salgado}

Considerando que a determinação de renina e aldosterona após manobras posturais e a administração de drogas, não tem muita especificidade no diagnóstico diferencial do hiperaldosteronismo primário, qual o valor diagnóstico do cateterismo de veias adrenais, para deteminação de aldosterona?

\section{Prof. Dr. Claudio Elias Kater}

Embora os procedimentos atuais de imagem sejam excelentes para a detecção de pequenas lesões adrenais, a facilidade e universalização de seu uso descortinaram o complexo problema dos incidentalomas. Passamos a encontrar, com freqüência, indivíduos com quadro bioquímico típico de hiperplasia, mas com uma imagem suspeita de adenoma adrenal, ou quadro bioquímico de adenoma, mas com anormalidades em ambas as adrenais. De qualquer maneira, antes de tudo eu recomendo que se estabeleça junto com uma equipe especializada de radiologistas, um protocolo apropriado para exploração das adrenais nos casos suspeitos de hiperaldosteronismo. A chance de se perder pequenos tumores adrenais, com diâmetros da ordem de 1,5 a $2 \mathrm{~cm}$, relativamente freqüentes, é significativa nas mãos de radiologistas pouco experientes e sem um protocolo comum de investigação. Deve ser lembrado, também, que embora a aparelhagem seja importante, o cuidado e a atenção com o procedimento em si são vitais. Aparelhos de última geração podem não detectar tumores pequenos se o paciente não for adequadamente instruído a não se movimentar e respirar corretamente durante o procedimento, por exemplo. Quando a suspeita bioquímica é fortemente favorável a um adenoma, mas uma imagem bem realizada for negativa, pode ser necessário indicar o cateterismo seletivo de veias adrenais, com coleta em separado de sangue para dosagem de aldosterona e cortisol, já que oscilações do ACTH podem elevar a produção de aldosterona. Aqui, também, há necessidade de um bom intervencionista para melhor acurácia diagnóstica.

\section{Prof. Dr. Marcello Delano Bronstein (médico assistente, Serviço de Endocrinologia e Metabologia HC-FMUSP)}

A resposta da hipertensão à espironolactona, nos casos de hiperaldosteronismo primário, sugere autonomia da adrenal e maior possibilidade de cura cirúrgica?

\section{Prof. Dr. Claudio Elias Kater}

Conforme publicamos há algum tempo, a resposta à administração de espironolactona, tanto dos níveis de potássio, que invariavelmente se elevam, quanto e especialmente dos níveis pressóricos, é preditiva de autonomia do sistema. Isto praticamente garante o prognóstico e o sucesso cirúrgico, quer a lesão seja um adenoma, quer seja uma hiperplasia primária. Esta forma peculiar de hiperplasia é uma das poucas que responde à redução de massa, diferente da hiperplasia simples ou idiopática, na qual mesmo a adrenalectomia total bilateral não consegue normalizar os níveis de pressão arterial elevados, embora normalize o potássio.

\section{Prof. Dr. Marcello Delano Bronstein}

Quando se deve investigar a reposta à dexametasona em casos de hiperaldosteronismo primário?

\section{Prof. Dr. Claudio Elias Kater}

Eu nunca tive a oportunidade de estudar um caso de hiperaldosteronismo supressível por dexametasona. Esta é uma entidade rara, de ocorrência familial e que acomete pacientes mais jovens. A suspeita é fortalecida pela presença de vários casos na família, razão pela qual a condição vem sendo designada de "hiperaldosteronismo familiar tipo l", em contraste com o subgrupo reportado recentemente por Richard Gordon e colaboradores. Esta nova forma, "hiperaldosteronismo familiar tipo 2", engloba casos familiares de adenomas produtores de aldosterona ou de hiperplasia idiopática, não supressíveis por dexametasona. Sempre que se 
encontrar mais de um caso na família, especialmente em jovens, deve-se indicar a supressão com dexametasona. Habitualmente a resposta é brilhante, tanto aguda como cronicamente. Como a condição resulta de uma anomalia genética, casos suspeitos de hiperaldosteronismo supressível por dexametasona podem ter amostras de DNA analisadas por um consórcio internacional. Após o PCR pode ser identificada a mutação responsável pela expressão da aldosterona-sintetase na zona fasciculada, tornando os casos suspeitos hoje em dia relativamente fáceis de serem diagnosticados. Deve-se ter cuidado com este diagnóstico bioquímico, uma vez que a administração aguda de dexametasona em doses baixas, pode reduzir substancialmente os níveis de aldosterona plasmática em casos de adenoma, suprimindo o componente ACTH dependente de sua produção.

\section{Dra. Maria Adelaide Albergaria Pereira (médica assistente, Serviço de Endocrinologia e Metabologia HC-FMUSP)}

A elevada prevalência de hiperaldosteronismo primário em pacientes hipertensos provavelmente se deva à presença de hiperaldosteronismo idiopático. Qual a importância prática desse diagnóstico? Isto vai mudar a conduta terapêutica?

\section{Prof. Dr. Claudio Elias Kater}

Se for possível detectar, numa população primariamente designada como de hipertensos sistêmicos idiopáticos, portanto sem etiologia definida, uma parcela que seja de causas definidas, certamente teremos melhor especificidade terapêutica. $\mathrm{O}$ que você questiona, com pertinência, é que se não existe no momento uma terapia específica para o hiperaldosteronismo idiopático, qual o interesse em identificá-los corretamente? Em primeiro lugar, a espironolactona (Aldactone ${ }^{\circledR}$ ), por ser um antagonista competitivo da aldosterona nos seus sítios de ação, reverte sistematicamente a hipocalemia e melhora os níveis pressóricos, embora sem normalizá-los. Contudo, isto é suficiente para que os pacientes tenham melhor prognóstico do que com um tratamento inespecífico. Entre os medicamentos inespecíficos mais receitados para o tratamento da hipertensão arterial, estão os diuréticos tiazídicos que, se usados indevidamente, trazem o risco de produzir ou agravar a hipocalemia, com seus efeitos indesejáveis inerentes. Além disso, pacientes com hiperaldosteronismo idiopático não diagnosticado podem necessitar de combinações de drogas para o controle da pressão arterial, que poderiam, do ponto de vista custo-benefício, ser desnecessárias ou até prejudiciais.
A possibilidade de se identificar casos de hiperaldosteronismo idiopático associada à perspectiva de se obter, a médio ou longo prazo, alguma terapia específica já justificaria a identificação deste grupo. Do ponto de vista prático, entretanto, não temos um tratamento único totalmente efetivo e, na medida em que estes pacientes não se beneficiam da cirurgia, talvez não haja mesmo uma vantagem evidente.

\section{Dr. Alexander Augusto de Lima Jorge (médico pós-graduando, Serviço de Endocrinologia e Metabologia do HC-FMUSP)}

Em qual paciente hipertenso, tratado com diurético e inibidores de enzima conversora, você suspenderia a medicação para explorar hiperaldosteronismo primário? Por quanto tempo o paciente deve ficar sem medicação para fazer as determinações de renina e aldosterona? Qual a medicação que não interfere com essas determinações? Alguns laboratórios fazem a dosagem da renina e não a determinação da atividade plasmática de renina. Nesses casos qual o valor recomendado para a relação aldosterona: renina?

\section{Prof. Dr. Claudio Elias Kater}

Não tenho resposta para nenhuma dessas perguntas no momento. Minhas considerações estão sendo revistas, na medida em que novas situaçóes e procedimentos estão sendo desenvolvidos. $\mathrm{Na}$ verdade, ainda estamos procurando obter respostas a algumas questôes: a relação aldosterona: APR está bem determinada e é fácil de ser empregada. Já a renina dosada por RIE, é um método relativamente recente que ainda carece de valores de referência. Temos um protocolo que pretende comparar os valores das duas determinações de renina e verificar se há alguma vantagem em redefinir novos limites de corte para a relação aldosterona:renina (por RIE). Alguns estudos nesta linha não encontraram correlação significante entre os dois métodos de dosagem da renina (APR e RIE), porque este é um processo dinâmico sem a necessidade de haver uma relação específica. Qual dos dois métodos será mais útil futuramente é ainda uma questão aberta.

Tradicionalmente, para se investigar casos suspeitos de hiperaldosteronismo primário, deve-se suspender toda e qualquer medicação que possa, potencialmente, interferir com o sistema renina-angiotensina, especialmente diuréticos, $\beta$-bloqueadores e inibidores da ECA. Quanto à relação aldosterona:APR, temos procurado não interferir na medicação do paciente, que é a real filosofia de um screening. Retira-se uma amostra de sangue durante consulta de rotina, em atividade ambulatorial normal, sem necessidade de repouso ou deam- 
bulação. O paciente mais idoso pode até sentar-se, mantendo os pés no chão, não devendo apenas estar deitado. Os dados apresentados de valores falsamente elevados ou falsamente baixos da relação aldosterona:APR têm justificativa teórica: $\beta$-bloqueadores suprimem a renina e podem resultar em valores falso-positivos. Se esta condição for muito prevalente deveremos interromper o uso de $\beta$-bloqueadores.Da mesma maneira, resultados falso-negativos - níveis reduzidos da relação em paciente com hiperaldosteronismo primário -, podem estar associados ao uso de diuréticos, elevando desproporcionalmente a renina. Talvez, também, possa ser necessário suspender este tipo de medicação, mas nessa fase inicial do screening preferimos não interferir em nada, para podermos conhecer melhor o perfil e comportamento deste teste.

\section{Dr. Jean Jorge Silva de Souza (médico residente, Serviço de Endocrinologia e Metabologia do HC-FMUSP)}

Um paciente portador de hiperaldosteronismo primário e de incidentaloma adrenal pode ter seu quadro funcional atribuído, erroneamente, ao tumor. Quando eu devo suspeitar dessa situação?

\section{Prof. Dr. Claudio Elias Kater}

Evidentemente, quando o diagnóstico bioquímico de hiperaldosteronismo por adenoma é ineqüívoco, a remoção da lesão deverá corrigir o quadro. De outra forma ele persistirá. Mas onde estará então a lesão primária, se o tumor removido era um incidentaloma? Eu não me recordo de ter visto tal situação na prática. Por outro lado, virtualmente todas as grandes séries de pacientes mostram persistência de hipertensão arterial em alguns casos operados, quer pelo fato dos indivíduos serem portadores de hipertensão essencial de base, quer pela longa exposição ao excesso de aldosterona, fazendo com que a pressão arterial se mantivesse fixa. Estes pacientes melhoram, mas não se curam da hipertensão; já uma eventual persistência de hipocalemia ou manutenção da supressão de renina, caracterizam o estado de hiperaldosteronismo, que pode ser comprovado pelas dosagens hormonais póscirúrgicas. É possível que a presença de um incidentaloma possa mimetizar ou encobrir uma lesão esperada, mas esta deve ser uma eventualidade muito rara.

\section{Dr. Marcelo Cidade Batista (médico assistente, Serviço de Endocrinologia e Metabologia do HC- FMUSP)}

Qual o kit que o senhor utiliza para as determinaçóes de aldosterona e atividade de renina plasmáticas?

\section{Prof. Dr. Claudio Elias Kater}

Nós usamos metodologia própria, desenvolvida na UNIFESP em colaboração com o Dr. José Gilberto Vieira e o Laboratório Fleury. Para a determinação da atividade plasmática de renina, empregamos um ensaio doméstico de geração de angiotensina, utilizando um anticorpo específico desenvolvido contra a angiotensina I. A aldosterona também é dosada por meio de um RIE doméstico com extração prévia. Este ensaio está sendo implementado com o emprego de um anticorpo mais específico, evitando a reatividade cruzada com outros esteróides incomuns, em especial aqueles produtos anômalos que podem estar elevados mais especificamente no hiperaldosteronismo primário. Idealmente, qualquer ensaio para esteróides para ser confiável deve ser precedido de extração e separação por cromatografia, em especial a HPLC. Estamos, neste momento, padronizando este procedimento.

\section{Dr. Marcelo Cidade Batista}

Quando se usa cromatografia, o valor diagnóstico da relação aldosterona-renina é o mesmo?

\section{Prof. Dr. Claudio Elias Kater}

Os valores mostrados na minha apresentação são, na verdade, de um estudo retrospectivo. Utilizando os dados de aldosterona e APR, dosados por ocasião do diagnóstico de hiperaldosteronismo primário, calculamos o valor da relação aldosterona:renina. Exceto 20 a 25 pacientes do nosso ambulatório na UNIFESP, a maioria destes dados foram colhidos no San Francisco General Hospital, ao longo dos últimos 25 anos, com metodologia própria daquela instituição, que contemplava cromatografia prévia em papel e, posteriormente, em HPLC. Analisando em retrospecto os vários subgrupos de hiperaldosteronismo que tínhamos publicado, acabamos descobrindo uma sub-população de hipertensos ditos essenciais que tinha a relação aldosterona:renina aumentada. Deveriam, portanto, ser portadores de hiperaldosteronismo previamente insuspeito. Os grupos bem estabelecidos tem faixas da relação aldosterona:renina bem estratificadas: todos os adenomas produtores de aldosterona tem realmente valores acima de 40 , geralmente na faixa dos 200 a 500, as hiperplasias têm valores acima de 25 , na faixa média de 50 , e os hipertensos essenciais habitualmente abaixo de 20 .

\section{Dr. Marcelo Cidade Batista}

Independente do método utilizado, a sua expectativa é a de que essa relação vai ser válida como screening? 


\section{Prof. Dr. Claudio Elias Kater}

Eu creio que sim. Mas aí voltamos para a pergunta anterior, se terá importância detectar especificamente os casos de hiperaldosteronismo idiopático. Parece-me que vocês tiveram aqui no HC-FMUSP apenas dois casos detectados neste último ano. Evidente que não precisamos esperar que o indivíduo tenha $1,5 \mathrm{mEq} / \mathrm{L}$ de potássio ou se apresente com tetraparesia para que se suspeite do diagnóstico. Estes são casos extremos. Níveis de potássio sérico na faixa de 3,2 a $3,5 \mathrm{mEq} / \mathrm{L}$, normalmente tidos como "normais" por boa parte dos médicos, devem ser considerados fortemente suspeitos. O objetivo é fazer o diagnóstico precocemente em pacientes com alteraçóes bioquímicas discretas. Idealmente, gostaríamos de poder detectar pacientes com hiperaldosteronismo primário mesmo que ainda normocalêmicos e/ou normotensos, através da elevação da relação aldosterona:APR, o índice mais sensível do excesso de aldosterona.

\section{Prof. Dr. Bernardo Léo Wajchenberg (Professor Emérito da FMUSP]}

Tenho dois pacientes com hiperaldosteronismo primário e tumor adrenal que não foram operados porque não tinham condições cirúrgicas e foram tratados com Aldactone ${ }^{\circ}$. Esses pacientes estão sem medicação há vários anos e permanecem normotensos, com aldosterona e renina normais, como se tivesse havido uma regressão, espontânea ou provocada pela espironolactona, do hiperaldosteronismo. Você conhece casos semelhantes?

\section{Prof. Dr. Claudio Elias Kater}

Eu não saberia explicar porque um indivíduo que tem hiperaldosteronismo por tumor comprovado bioquimicamente, cujo tratamento prolongado com Aldactone ${ }^{\circledR}$ reverteu o quadro clínico, mantém-se normal depois de suspensa a medicação. Diria que é uma questão de tempo para a doença ressurgir. Existe, também, a questão da presença dos corpúsculos de espironolactona que, verdadeiramente, nunca foi esclarecida. Jerome Conn descreveu isso em tumores, mas os corpúsculos são corpos inertes, grandes, muito bem identificados, que comprometem a mitocondria da célula tumoral. Talvez tenham, por esta razão, a característica de "envenenar" o tecido neoplásico interferindo no processo de respiração celular, de maneira que um paciente que use espironolactona por tempo prolongado possa tornar o tumor funcionalmente inoperante. Talvez seja interessante reavaliar estes seus pacientes agora para constatar uma eventual "cura". Conheço vários casos de pacientes que recusaram a cirurgia e que vinham usando Aldactone ${ }^{\circledast}$ há mais de 5-
7 anos, mantendo-se muito bem controlados com doses até reduzidas da droga. Como não ousamos suspender o tratamento deles, não sei dizer sobre uma possível "cura". Em alguns pacientes com aldosteronoma, que vinham usando Aldactone ${ }^{\circledR}$ por pouco tempo, pedimos autorização para suspender a droga a estudar a reinstituição do quadro clínico. Este tempo curto, obviamente não foi suficiente para torná-los quiescentes.

\section{Prof. Dr. Helio Bisi (médico assistente, Serviço de Patologia do HC-FMUSP)}

$\mathrm{Na}$ paciente em questão havia adenoma coincidindo com hiperplasia da glomerulosa. Como interpretar esses achados? Devemos supor que houve evolução da hiperplasia para adenoma?

\section{Prof. Dr. Claudio Elias Kater}

No caso apresentado, observou-se níveis baixos de aldosterona por algum tempo após a cirurgia, comprovando a retirada de uma lesão funcionante qualquer que tenha sido ela. Embora tenham sido descritos casos de hiperplasia adrenal unilateral, parece-me pouco provável que este seja o caso. Se a paciente tivesse tido um quadro de hiperplasia na qual se desenvolveu por alguma razão um adenoma, eu esperaria que a outra glândula continuando hiperplasiada não houvesse supressão da aldosterona no período pós-cirúrgico. Nós pudemos verificar em alguns de nossos casos de adenoma que existe uma hiperplasia da zona glomerulosa ipsilateral e não, necessariamente, circunjascente ao adenoma ou peri-adenomatosa. O mecanismo provável para explicar esta concomitância de achados parece envolver a secreção local e ação parácrina de IGFs e outros fatores de crescimento produzidos pelas células tumorais, resultando em hiperplasia focal. Não tenho conhecimento da prevalência deste tipo de hiperplasia associada ao tumor. Nem tampouco de sua extensão, se apenas circunscrita ou focal, ou envolvendo toda a zona glomerulosa do córtex ipsilateral. O que seria natural de se esperar, a atrofia da zona glomerulosa remanescente, na realidade não ocorre com frequência.

\section{Prof. Eder C.R. Quintão (Professor Titular de Endocrinologia da FMUSP)}

Como o senhor vê a perspectiva do uso rotineiro de HPLC como método de análise dos hormônios esteróides? Haveria necessidade de se acoplar um espectrômetro de massa?

\section{Prof. Dr. Claudio Elias Kater}

Este comentário, absolutamente pertinente, pode ser visto de duas maneiras: em um laboratório de pesquisa, 
gostaríamos de obter informações corretas através de dosagens precisas. Mecanismos fisiopatológicos são desvendados com a certeza e a precisão metodológica. Dosagens imprecisas ou conflitantes não respondem a algumas questões cruciais e a metodologia parece estar envolvida no processo. Por outro lado, como a maioria dos diagnósticos da patologia adrenal não necessita, obrigatoriamente, de números precisos, determinações que utilizam kits comerciais de um laboratório de rotina são toleradas. Eu tive a oportunidade de vivenciar dois dos mais sofisticados laboratórios de referência em esteróides no mundo: o de Edward Biglieri, em San Francisco e o Cedric Shackleton, em Oakland. Biglieri antes de se formar médico era, como Shackleton, bioquímico, e ambos absolutamente fascinados por esteróides. Ambos descreveram inúmeras técnicas de separação utilizadas hoje em dia nos laboratórios de pesquisa. Empregavam cromatografia em papel desde os anos 60 , e sempre utilizavam cromatografia preparatória para dosagem de esteróides no plasma ou urina antes dos ensaios. Diziam que sem cromatografia não adiantava nada dosar esteróides, dada sua incrível semelhança estrutural e facilidade de reatividade cruzada, por melhor que fosse o anticorpo empregado no RIE ou qualquer outro detector. A cromatografia líquida de alta performance era utilizada no laboratório de Biglieri, enquanto a cromatografia a gás e espectrometria de massa, era empregada por Shackleton para avalição de um sem número de metabólitos urinários de esteróides

Evidente que, além do alto custo envolvido neste processo, quer com o HPLC quer com o GCMS, a quantidade de trabalho refinado também é substancial. Além disso, não se pode ter em qualquer laboratório amostras de rotina passando por HPLC ou GC-MS porque demorariam um tempo enorme e iriam custar pelo menos 10 vezes mais.

Do ponto de vista de resultados específicos, se realmente se quiser separar sinal de ruído, inegavelmente precisamos contar com separação por cromatografia.

\section{REFERÊNCIAS SELECIONADAS}

1. Anwar YA, White WB, Mansoor GA, Tendler BE. Hyperaldosteronism is a common cause of secondary hypertension missed by primary care physicians and associated with normokalemia. Am J Hypertens 1998;1 1:199A.

2. Arteaga E, Biglieri EG, Kater CE. Aldosterone-producing adrenocortical carcinoma: pre-operative recognition and course in three cases. Ann Intern Med 1984;101:316-21.

3. Berglund G, Anderssin O, Wilhalmsen L. Prevalence of primary aldosteronism and secondary hypertension studies in random population sample. Br Med J 1976;2:554-56.
4. Biglieri EG, Irony I, Kater CE. Identification and implications of new types of mineralocorticoid hypertension. J Steroid Biochem 1989;32(1B):199-204.

5. Blumenfeld JD, Sealey JE, Schlussel Y. Diagnosis and treatment of primary aldosteronism. Ann Intern Med 1994; 121:877-85.

6. Bravo EL. Primary aldosteronism: issues in diagnosis and management. Endocrinol Metab Clin North Am 1994;23:271-83.

7. Conn JW. Presidential address: Part I. Painting background. Part II. Primary aldosteronism, a new clinical syndrome. J Lab Clin Med 1955;45:3-17.

8. Conn JW. Plasma renin activity in primary aldosteronism. JAMA 1964;190:554-56.

9. Conn JW, Knopf RF, Nesbit RM. Clinical characteristics of primary aldosteronism from an analysis of 145 cases. Am J Surg 1964;107:159-72.

10. Danielson M, Dammstron BG. The prevalence of secondary curable hypertension. Acta Med Scand 1981;209:451-55.

11. Dluhy RG, Lifton RP. Glucocorticoid-remediable aldosteronism. Endocrinol Clin North Am 1994;23:285-97.

12. Fardella CE, Mosso L, Gomez-Sanchez C, Cortes P, Soto J, Gomez L, et al. Primary hyperaldosteronism in essential hypertensives: prevalence, biochemical profile, and molecular biology. J Clin Endocrinol Metab 2000:85:1863-7.

13. Fontes RG, Kater CE, Biglieri EG, Irony I. Reassesment of the predictive value of the postural stimulation test in primary aldosteronism. Am J Hypertens 1991;4:786-91.

14. Fraser R, Murray GD, Connel JMC. Conn's syndrome: no longer a needle in haystack? Clin Endocrinol 1998;6:709-10.

15. Gallay BJ, Toivila B, WasylenkoM, Davidson RC. Insensitivity of the plasma aldosterone renin ratio to antihypertensive medication in screening for primary hyperaldosteronism (Abstract). Am J Hypertens 1997; 10(Part 2):31A.

16. Gordon RD, Gomez-Sanchez CE, Hamlet SM. Angiotensinresponsive aldosterone producing adenoma masquerades as idiopathic hyperaldosteronism or low renin essential hypertension. J Hypert 1987;5[suppl 5]:S103-06.

17. Gordon RD, Stowasser M, Klemm AS. Primary hyperaldosteronism - some genetic, morphological, and biochemical aspects of subtypes. Steroids 1995;60:35-41.

18. Gordon RD, Stowasser M, Tunny TJ, Klemm SA, Rutherford JC. High incidence of primary aldosteronism in 199 patients referred with hypertension. Clin Exp Pharmacol Physiol 1994;21:315-18.

19. Gordon RD, Zlesak MD, Tunny TJ, Stowasser M, Klemm SA. Evidence that primary aldosteronism may not be uncommon: $12 \%$ among antihypertensive drug trial volunteers. Clin Exp Pharmacol Physiol 1993;20:296-8.

20. Hiramatsu K, Yamada T, Yukimura Y. A screening test to identify aldosterone-producing-adenoma by measuring plasma renin activity. Arch Intern Med 1981;141:1589-93.

21. Irony I, Kater CE, Biglieri EG, Shackleton CHL. Correctable subsets of primary aldosteronism: primary adrenal hyperplasia and renin-responsive adenoma. Am J Hypert 1990;3:576-82.

22. Kater CE, Biglieri EG, Schambelan M, Arteaga E. Studies of impaired aldosterone response to spironolactone-induced renin and potassium elevations in adenomatous but not 
hyperplastic primary aldosteronism. Hypertension 1983;5[suppl V]:V115-V21.

23. Lim PO, Brennan $G$, Shiels $P$. Unexpectedly high prevalence of primary aldosteronism in a hypertension clinic population of Dundee. J Endocrinol 1988; 156 (suppl):p22.

24. Lim PO, Rodgers $P$, Cardale K, Watson AD, MacDonald TM. Potentially high prevalence of primary aldosteronism in a primary-care population. Lancet 1999;353:40.

25. Lins P-E, Adamson U. Plasma aldosterone-plasma renin activity ratio. A simple test to identify patients with primary aldosteronism. Acta Endocrinol (Copenh) 1986; 113:56469.

26. Loh K-C, Koay ES, Khaw M-C, Emmanuel SC, Young Jr WF. Prevalence of primary aldosteronism among Asian hypertensive patients in Singapore. J Clin Endocrinol Metab 2000;85:2854-9.

27. Massien-Simon C, Battaglia C, Chatellier G, Guyene $T$, Duclos JM, Plouin PF. Primary aldosteronism: diagnostic and prognostic value of potassium, renin, aldosterone and the aldosterone/renin ratio. Presse Med 1995;24:1238-42.

28. McAreavey D, Murray G.D, Lever AF, Robertson JIS. Similarity of idiopathic aldosteronism and essential hypertension. A statistical comparison. Hypertension 1983;5:116-21.

29. McKenna TJ, Sequeira SJ, Heffernan A, Chambers J, Cunningham S. Diagnosis under random conditions of all disorders of the renin-angiotensin-aldosterone axis, including primary aldosteronism. J Clin Endocrinol Metab 1991;73:952-57.

30. Nadler JL, Hsueh W, Horton R. Therapeutic effect of calcium channel blockade in primary aldosteronism. J Clin Endocrinol Metab 1985;60:896-99.

31. Rossi PG, Rossi E, Pavan E, Rosati N, Zecchel R, Semplicini A, et al. Screening for primary aldosteronism with a logistic multivariate discriminate analysis. Clin Endocrinol (Oxf.) 1998;49:713-23

32. Sinclair AM, Isles CG, Brown I, Cameron H, Murray GD, Robertson JWK. Secondary hypertension in a blood pressure clinic. Arch Intern Med 1987;147:1289-93.

33. Stewart PM. Mineralocorticoid hypertension. Lancet 1999;353:1341-47.

34. Stowasser M, Gordon RD, Tunny TJ. Familial hyperaldosteronism type II: five families with a new variety of primary aldosteronism. Clin Exp Pharmacol Physiol 1992;19:319-22.
35. Streeten DHP, Tomycz N, Anderson GH Jr. Reliability of screening methods for the diagnosis of primary aldosteronism. Am J Med 1979;67:403-13.

36. Sutherland DJA, Ruse JL, Laidlaw JC. Hypertension, increased aldosterone secretion and low plasma renin activity relieved by dexamethasone. Can Med Assoc J 1966;95:1109-20.

37. Torpy DJ, Gordon RD, Lin J-P. Familial hyperaldosteronism type-II: description of a large kindred and exclusion of the aldosterone synthase (CYP11B2) gene. J Clin Endocrinol Metab 1998;83:3214-18.

38. Weinberger MH, Fineberg NS. The diagnosis of primary aldosteronism and separation of two major subtypes. Arch Intern Med 1993;153:2125-29.

39. Weisnagel SJ, Gagner M, Breton G, et al. Laparoscopic adrenalectromy. Endocrinologist 1996;6:169-78.

40. Widimsky J, Dvorakova J, Kopecka J, Matejovska H, Tesar D, Krivanek J, Horak J, Marek J. Is primary aldosteronism the most frequent form of secondary hypertension? Cor et Vasa $1996 ; 38: 239-42$

41. Young Jr WF. Primary aldosteronism: Update on diagnosis and treatment. Endocrinologist 1997;7:213-21.

Endereço para correspondência:

Maria Adelaide Albergaria Pereira

Avenida Dr. Enéas de Carvalho Aguiar, 255

PAMB, 80 andar - Bloco 3

05403-000 São Paulo, SP

e-mail: simnendoc.@hcnet.usp.br

FAX: 3088-6964 